\title{
Potencial Alelopático de Plantas de Acapu (Vouacapoua americana): Efeitos Sobre Plantas Daninhas de Pastagens ${ }^{1}$
}

\author{
Allelopathic Potential of “Acapu” (Vouacapoua americana) Plants: Effects on Pasture Weed
}

\author{
SOUZA FILHO, A.P.S. ${ }^{2}$ e ALVES, S.M. ${ }^{3}$
}

\begin{abstract}
RESUMO - Extratos aquosos de folhas e cascas de plantas de acapu (Vouacapoua americana) foram preparados nas concentrações de 0, 1, 2, 3 e 5\% (v/v), visando identificar e caracterizar a atividade potencialmente alelopática dessa espécie. Analisaram-se os efeitos dos extratos sobre a germinação de sementes e o alongamento da raiz primária das plantas daninhas malícia (Mimosa pudica) e malva (Urena lobata). Os bioensaios de germinação foram desenvolvidos em condições de $25^{\circ} \mathrm{C}$ e fotoperíodo de 12 horas. Para os bioensaios de alongamento da raiz primária, as condições estabelecidas foram de $25^{\circ} \mathrm{C}$ e fotoperíodo de 24 horas. Os resultados obtidos indicaram variações de respostas em função da fonte do extrato aquoso, do parâmetro analisado e da concentração do extrato. As reduções observadas tanto na germinação como no alongamento da raiz primária foram crescentes com o aumento da concentração do extrato, sendo os efeitos mais intensos observados na concentração de $5 \%$. Independentemente da espécie receptora e do parâmetro analisado, o extrato preparado a partir das cascas do acapu evidenciou maior atividade alelopática inibitória. O alongamento da raiz primária foi o parâmetro mais sensivel aos efeitos potencialmente alelopáticos do que a germinação das sementes. Comparativamente, cascas e folhas apresentaram diferenças em relação às classes de substâncias químicas. Nas cascas foram encontradas cumarinas que não estavam presentes nas folhas, as quais, por sua vez, apresentaram esteróides e triterpenóides, que não foram identificados nas cascas do acapu.
\end{abstract}

Palavras-chave: alelopatia, germinação, cumarinas, esteróides e triterpenóides.

\begin{abstract}
Aqueous extracts from leaves and bark of "Acapu" plants were prepared in concentration levels of $0,1,2,3$ and $5 \%$ to identify and characterize potential allelopathic activity of such plants. The extract effects on seed germination and primary root elongation of pasture weeds, such as Mimosa pudica and Urena lobata, were analyzed. The germination bioassays were developed under $25^{\circ} \mathrm{C}$ and a photoperiod of 12 hours. For the primary root elongation, the bioassay conditions were $25^{\circ} \mathrm{C}$ and photoperiod of 24 hours. The results indicated a variation in response, according to the source of aqueous extract, the analyzed parameter and the extract concentration. The reductions observed both in germination and primary root elongation increased with the increase of extract concentration. The most intense effects were observed at an extract concentration level of 5\%. Regardless of the receiving species and the analyzed parameter, the extract prepared from the bark showed greater inhibiting allelopathic activity. The parameter primary root elongation was more sensitive to the potential allelopathic effects than seed germination. Comparatively, bark and leaves showed differences in relation to the chemical compound classes. Cumarins were identified in the bark but not in the leaves, while steroids and triterpenoids were observed in the leaves but not in the bark.
\end{abstract}

Key words: allelopathy, germination, Cumarins, steroids and triterpenoids.

1 Recebido para publicação em 16/11/1999 e na forma revisada em 16/3/2000.

2 Eng.-Agr ${ }^{\circ}$., Doutor, pesquisador da Embrapa Amazônia Oriental, Trav. Dr. Enéas Pinheiro, S/N, 66095-100 Belém, Pará. <apedro@cpatu.embrapa.br>; ${ }^{3}$ Eng. Quim., M.S., pesquisador da Embrapa Amazônia Oriental. <sergio@cpatu.embrapa.br> 


\section{INTRODUÇÃO}

Alelopatia - efeitos diretos e indiretos de uma planta sobre outra - é um fenômeno que ocorre largamente em comunidades de plantas cultivadas e tem sido postulado como um dos mecanismos de interferência que determinadas plantas impõem sobre outras em suas imediações, por meio da produção de substâncias químicas que são liberadas para o meio ambiente de diferentes formas, como lixiviação de tecidos vivos e mortos da planta, exsudação radicular, decomposição de tecidos e volatilização (Rice, 1984). Este fenômeno tem sido reconhecido como um importante mecanismo ecológico, o qual influencia a dominância da vegetação, a sucessão de plantas, a formação de comunidades de plantas, a vegetação clímax e a produtividade das culturas (Chou, 1986; Smith, 1989). Essa característica tem merecido, por parte da comunidade científica, cada vez mais atenção em razão das possibilidades que oferece como estratégia de controle de plantas daninhas, em especial nos ecossistemas de pastagens cultivadas.

Nos últimos anos, tem crescido o interesse pelos sistemas agroflorestais como alternativa para a exploração de áreas tropicais, especialmente onde predominam os solos ácidos e de baixa fertilidade. Estes sistemas de exploração têm se mostrado mais equilibrados sob o ponto de vista ambiental e da sustentabilidade do que aqueles tradicionalmente em uso. Desde que em sistemas agroflorestais as árvores sejam cultivadas em associação com outras culturas, como é o caso de pastagens, a utilização de espécies arbóreas com características desejáveis, a exemplo da fixação de nitrogênio pelas leguminosas, é fundamental para a estabilidade e o sucesso do sistema. Paralelamente, espécies com atividade alelopática podem desempenhar papel crucial na estabilidade dos sistemas agroflorestais, em especial na redução da infestação de plantas invasoras.

Nesse contexto, a região amazônica possui adicional vantagem, por apresentar rica biodiversidade de espécie de plantas, podendo contribuir não só com o fornecimento de espécies arbóreas com propriedades desejáveis para compor sistemas agroflorestais estáveis ao longo do tempo, como também fornecendo novas estruturas químicas com possibilidades de uso na agricultura, por meio da produção de biodefensivos agrícolas.

As fontes disponíveis para agentes alelopáticos podem ser classificadas em três grupos: a) metabólitos secundários originários de espécies pertencentes a um mesmo ecossistema estudado; b) metabólitos secundários originários de outros ecossistemas, não necessariamente relacionados com um determinado estudo; e c) síntese similar de aleloquímicos (Macias, 1995). Considerando que o acapu é uma espécie arbórea nativa da floresta amazônica e que ainda não foi utilizada em sistemas agroflorestais, este estudo se insere na estratégia "b" estabelecida anteriormente.

O objetivo desta pesquisa foi identificar e caracterizar a atividade potencialmente alelopática em plantas de acapu.

\section{MATERIAL E MÉTODOS}

Cascas do tronco e folhas verdes de plantas de acapu (Vouacapoua americana Aublet; Família Leguminosae - Caesalpinoideae) foram colhidas em área do Campo Experimental da Embrapa Amazônia Oriental, localizado no município de Moju, Estado do Pará. O material foi seco em estufa com circulação de ar forçada por 96 horas, à temperatura de $39^{\circ} \mathrm{C}$. Posteriormente, foi triturado em moinho faca tipo Willey e acondicionado em sacos de plástico. Obtiveram-se $3,5 \mathrm{~kg}$ de casca e 3,0 kg de folhas secas e moídas.

Para cada quilo de material seco triturado foram adicionados nove litros de água destilada, parcelada em três etapas. Para cada fracionamento de 1:3 (material seco:água destilada), a mistura permanecia em infusão por 24 horas, filtrando-se em seguida com o auxílio de uma bomba a vácuo e acrescentando-se, ao material remanescente, mais três litros de água, e assim sucessivamente, até completar os nove litros de água estabelecidos. O resultado desse processo foi a obtenção do extrato bruto aquoso, o qual foi liofilizado.

O material liofilizado serviu de base para o preparo dos extratos aquosos nas concentrações de 0, 1, 2, 3 e 5\% (v/v). A concentração máxima de $5 \%$ foi estipulada considerando-se que é aquela mais comumente utilizada em bioensaios de alelopatia usando extratos aquosos (Stowe, 1979). Os extratos aquosos 
foram deixados em repouso por seis horas, sendo então novamente filtrados.

Os efeitos foram avaliados sobre a germinação de sementes e o desenvolvimento da radícula de duas das principais plantas invasoras que ocorrem com freqüência em áreas de pastagens cultivadas na região amazônica, que são: malícia (Mimosa pudica Mill) e malva (Urena lobata L.). Os bioensaios de germinação foram desenvolvidos em condições controladas de $25{ }^{\circ} \mathrm{C}$ de temperatura constante e fotoperíodo de 12 horas. A germinação foi monitorada em períodos de 15 dias, com contagens diárias e eliminação das sementes germinadas. Utilizaram-se 50 sementes para cada caixa gerbox transparente, de $11 \times 11 \mathrm{~cm}$. Foram consideradas sementes germinadas as que apresentavam extensão da raiz primária igual ou superior a 2 mm (Juntila, 1976; Duran \& Tortosa, 1985). Os bioensaios de desenvolvimento radicular foram conduzidos em câmaras, em condições de $25{ }^{\circ} \mathrm{C}$ de temperatura constante e fotoperíodo de 24 horas. Em cada caixa gerbox transparente, de $11 \times 11 \mathrm{~cm}$, foram colocadas seis sementes pré-germinadas. Após 10 dias de crescimento, mediu-se o comprimento da radícula.

Através de um Osmometer, determinou-se o potencial osmótico de cada extrato aquoso, sendo o valor máximo obtido de $0,13 \mathrm{MPa}$. Testes preliminares para avaliar os efeitos do potencial osmótico na germinação das sementes de malícia e malva foram realizados. Para isso, foram preparadas soluções aquosas a 0,0 ; 0,1; e 0,2 MPa, utilizando-se polietilenoglicol 6000 . Os resultados indicaram que a germinação não variou em função do potencial osmótico até 0,2 MPa. Dessa maneira, e considerando o valor máximo de $0,13 \mathrm{MPa}$, foram desconsiderados os seus efeitos sobre os resultados, e a avaliação dos extratos aquosos foi realizada tendo como contraste (testemunha) a água destilada. Foi estabelecido o volume de $8 \mathrm{ml}$ para cada caixa gerbox, tanto para os extratos como para a água. Os extratos foram adicionados apenas uma vez, quando do início dos bioensaios, sendo, a partir de então, adicionada apenas água destilada sempre que necessário.

O "screening" fitoquímico para a identificação das principais classes de substâncias químicas com atividades alelopáticas presentes nos extratos aquosos das duas frações da planta foi realizado conforme os procedimentos descritos por Assunção \& Morita (1968) e Ugaz (1988).

O delineamento experimental para os bioensaios de germinação e de alongamento da radícula foi o de blocos ao acaso com três repetições. Os resultados foram analisados por regressão polinomial. As análises foram realizadas com o programa SAS (Sas, 1989).

\section{RESULTADOS E DISCUSSÃO}

A germinação de sementes das duas espécies receptoras variou em função da fonte e da concentração dos extratos. Os resultados obtidos indicaram relação inversa entre a concentração do extrato e a germinação das sementes, sendo as reduções mais intensas obtidas na concentração de 5\%, tanto para o extrato aquoso da casca (Figura 1A) como das folhas (Figura 1B). A análise de regressão polinomial indicou relação quadrática entre a germinação das sementes e a variação na concentração dos extratos aquosos das cascas e das folhas do acapu (Tabela 1).

Quando testado na concentração de 1\%, o extrato aquoso da casca praticamente não promoveu efeitos potencialmente alelopáticos inibitórios na germinação das sementes das espécies de invasoras, em relação ao tratamento considerado testemunha (água destilada). Resultados semelhantes foram também verificados com relação ao extrato aquoso das folhas, para a mesma concentração de 1\%. Aparentemente, essa concentração de substâncias alelopáticas, solúveis em água, presentes nos extratos aquosos está abaixo daquela concentração exigida para reduzir, de forma expressiva, a germinação das sementes dessas duas plantas invasoras.

O extrato aquoso das cascas efetivou reduções máximas da ordem de 75,55 e 54,34\% na germinação das sementes da malícia e da malva, respectivamente, enquanto as reduções máximas promovidas pelos extratos de folhas, para as duas plantas invasoras, foram de 24,76 e $43,12 \%$, respectivamente, indicando maior potencial alelopático inibitório do extrato aquoso das cascas em relação ao das folhas. Esses resultados indicam, por um lado, que os efeitos potencialmente alelopáticos dependem da concentração em que a substância alelopática está presente nos extratos. Por outro lado, o 
fator fonte da substância parece ter, também, importância.

À semelhança dos efeitos observados sobre a germinação das sementes das duas espécies receptoras, o alongamento da radícula apresentou variações em função da fonte e da concentração dos extratos. Tendo por base os resultados obtidos para o tratamento testemunha (água destilada), o alongamento da radícula esteve inversamente relacionado à concentração do extrato, independentemente da espécie receptora, sendo os efeitos mais intensos observados na concentração de 5\% (Figura 2A e B). A análise de regressão polinomial para os efeitos da concentração do extrato e para o alongamento da radícula indicou relação quadrática entre essas variáveis, sendo as equações apresentadas na Tabela 1.

A

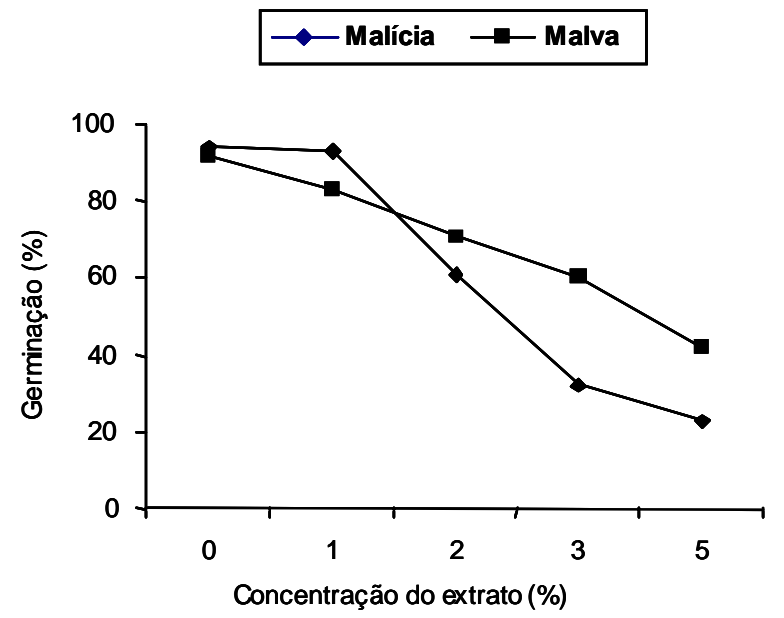

Quando testado na concentração de 1\%, o extrato aquoso da casca promoveu efeitos potencialmente alelopáticos inibitórios da ordem de $43,2 \%$ no desenvolvimento da radícula da invasora malícia e de $32,3 \%$ na malva, em relação ao tratamento testemunha. Para extrato aquoso de folhas na mesma concentração, as reduções foram da ordem de 16,11 e 14,6\% para malícia e malva, respectivamente. Embora nessa concentração os extratos não tenham promovido efeitos alelopáticos sobre a germinação de sementes das duas plantas invasoras, as reduções efetivadas no desenvolvimento da radícula dessas plantas é um indicativo de que o alongamento da radícula aparentemente é um fator mais sensivel aos efeitos potencialmente alelopáticos do que a germinação de sementes.

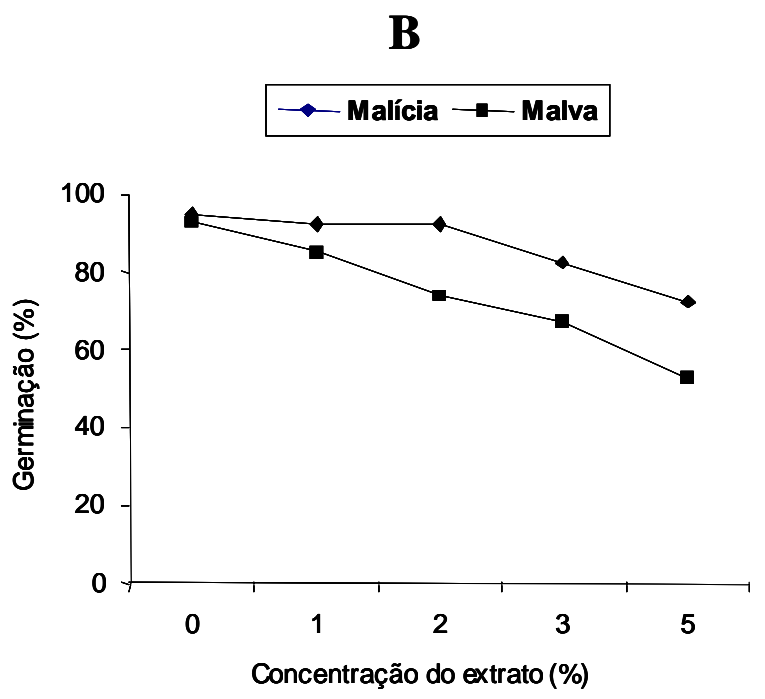

Figura 1 - Efeitos dos extratos aquosos da casca (A) e de folhas (B) de acapu sobre a germinação de sementes de duas plantas invasoras de pastagens.

Tabela 1 - Equações de regressão polinomial que expressam a relação entre as variáveis estudadas

\begin{tabular}{|c|c|c|}
\hline \multirow{2}{*}{ Espécie } & \multicolumn{2}{|c|}{ Extrato aquoso } \\
\hline & Cascas & Folhas \\
\hline \multicolumn{3}{|c|}{ Germinação } \\
\hline Malícia & $\hat{\mathrm{Y}}=101,86-24,36 \mathrm{X}+1,61 \mathrm{X}^{2} ; \mathrm{R}^{2}=0,90^{* *}$ & $\hat{\mathrm{Y}}=95,69-2,17 \mathrm{X}-0,53 \mathrm{X}^{2} ; \mathrm{R}^{2}=0,93^{* *}$ \\
\hline Malva & $\hat{\mathrm{Y}}=93,28-11,51 \mathrm{X}+0,27 \mathrm{X}^{2} ; \mathrm{R}^{2}=0,99 * *$ & $\hat{\mathrm{Y}}=94,12-10,37 \mathrm{X}+0,44 \mathrm{X}^{2} ; \mathrm{R}^{2}=0,94^{*}$ \\
\hline \multicolumn{3}{|c|}{$\begin{array}{l}\text { Alongamento da radícula } \\
\end{array}$} \\
\hline Malícia & $\hat{\mathrm{Y}}=2,03-0,71 \mathrm{X}+0,09 \mathrm{X}^{2} ; \mathrm{R}^{2}=0,93^{* *}$ & $\hat{\mathrm{Y}}=1,78-0,25 \mathrm{X}+0,03 \mathrm{X}^{2} ; \mathrm{R}^{2}=0,88^{*}$ \\
\hline Malva & $\hat{\mathrm{Y}}=4,24-1,32 \mathrm{X}+0,12 \mathrm{X}^{2} ; \mathrm{R}^{2}=0,98^{* *}$ & $\hat{\mathrm{Y}}=4,13-0,28 \mathrm{X}+0,02 \mathrm{X}^{2} ; \mathrm{R}^{2}=0,94^{* *}$ \\
\hline
\end{tabular}


A

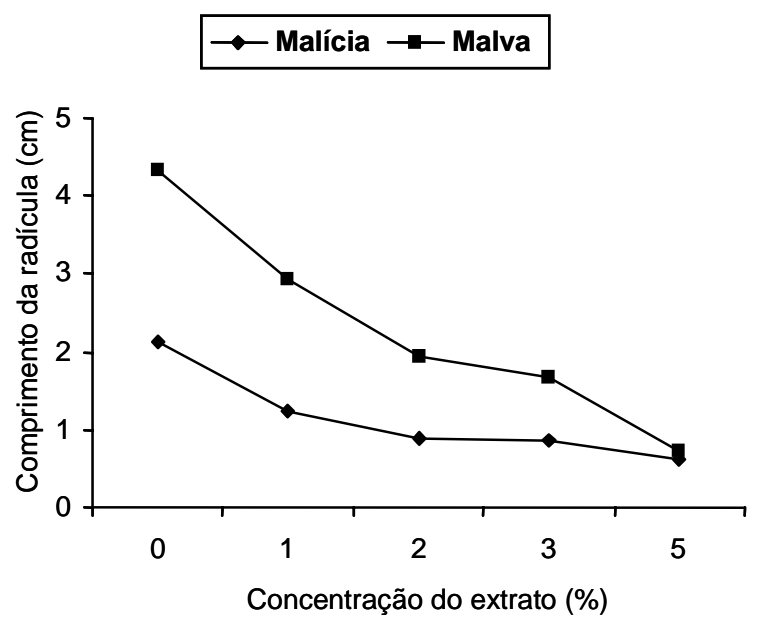

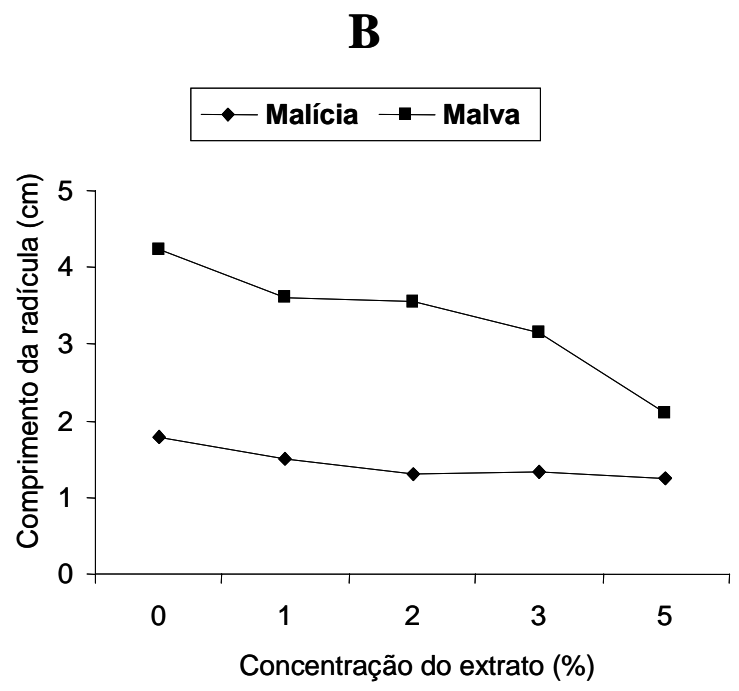

Figura 2 - Efeitos dos extratos aquosos da casca (A) e de folhas (B) de acapu sobre o alongamento da radícula de duas plantas invasoras de pastagens.

Comparativamente, o extrato aquoso das cascas apresentou maior potencial fitotóxico para reduzir o alongamento da radícula do que o extrato preparado a partir das folhas verdes das plantas do acapu (Figura 2A e B). Na concentração de $5 \%$, o desenvolvimento da radícula foi $70,42 \%$ menor do que no tratamento testemunha para a espécie malícia e $84,14 \%$ para a malva, enquanto para a mesma concentração o extrato aquoso das folhas efetivou reduções da ordem de $30,0 \%$ e 50,3\% para a malícia e a malva, respectivamente. Esse resultado repete aqueles obtidos para os efeitos dos extratos sobre a germinação das sementes (Figura 1A e B) e parece confirmar as cascas das plantas de acapu como principal fonte de substâncias alelopáticas, solúveis em água.

Os efeitos promovidos pelos extratos aquosos sobre a germinação das sementes e o alongamento da radícula assumem aspecto ecológico importante na utilização de plantas de acapu em áreas de pastagens cultivadas como estratégia de manejo, visando o controle das plantas invasoras. A redução no percentual de germinação das sementes pode funcionar como barreira ao fluxo de novos indivíduos de plantas de invasoras para as áreas de pastagens, resultando na formação de estandes mais puros de gramíneas e, ou, leguminosas forrageiras. Paralelamente, as inibições impostas ao desenvolvimento do sistema radicular impõem às plantas invasoras restrições ao seu potencial competitivo, o que favorece as espécies cultivadas, que podem se beneficiar dos recursos naturais disponíveis, como água e nutrientes. O principal reflexo desses dois aspectos será o aumento da produtividade e da longevidade das pastagens cultivadas. Dessa maneira, o uso de plantas de acapu para compor sistemas agroflorestais parece ser extremamente positivo não só do ponto de vista agronômico como do ambiental.

Teoricamente, todas as plantas são potencialmente capazes de sintetizar compostos com propriedades alelopáticas. Essa capacidade é menos prevalente nas plantas cultivadas e suas variedades comerciais. No entanto, essa característica era mais comum nos precursores selvagens das atuais plantas cultivadas, as quais se capacitaram para competir com outras plantas a fim de garantir não só a formação de estandes puros, como também de se defender de seus inimigos naturais (Bansal \& Bhan, 1993). Aparentemente, todas as partes das plantas podem conter substâncias alelopáticas. As informações disponíveis mostram que as substâncias químicas com atividades alelopáticas não se distribuem uniformemente nos diversos órgãos das plantas, podendo a maior concentração estar tanto nas folhas como nas raízes ou cascas do tronco de espécies arbóreas (Souza Filho et al., 1997; Corcera et al., 1992; Heisey, 1990; Rao, 1990; Friedman \& Waller, 1983). Em diferentes bioensaios, essas 
substâncias já foram encontradas em folhas, colmos, flores, rizomas, raízes, frutos, sementes e cascas de diferentes espécies de plantas (Smith \& Martin, 1994; Friedman \& Waller, 1983; Cope, 1982; Young \& Bartolomew, 1981; Putnam \& DeFrank, 1982; Heisey, 1990; Souza Filho, 1995). Neste trabalho, as cascas foram a principal fonte de substâncias potencialmente alelopáticas, solúveis em água.

Compostos com propriedades alelopáticas altamente diversificados quimicamente são comumente encontrados nas plantas superiores, e a quantidade e a composição destes podem variar com a espécie estudada (Putnam, 1985). Várias substâncias químicas relacionadas com alelopatia têm sido descritas em detalhes por autores como Rice (1984) e Putnam \& Tang (1986). Whittaker \& Feeny (1971) classificaram esses produtos secundários em cinco categorias principais: terpenóides, esteróides, alcalóides, acetogeninas e fenilpropanóides. Rice (1984) apresentou um classificação mais ampla desses compostos, envolvendo quinonas, taninos, flavonóides e outros. Dentre essas classes, foram identificados alcalóides e flavonóides como comuns às cascas e folhas do acapu; cumarinas, às cascas; e esteróides e triterpenóides, às folhas (Tabela 2).

Tabela 2 - Principais classes de aleloquímicos identificadas nas cascas e folhas do acapu

\begin{tabular}{|l|c|c|}
\hline \multirow{2}{*}{ Classes de aleloquímicos } & \multicolumn{2}{|c|}{ Parte da planta } \\
\cline { 2 - 3 } & Folhas & Casca \\
\hline Ácidos Orgânicos & $\mathrm{N}$ & $\mathrm{N}$ \\
Açúcares Redutores & $\mathrm{P}$ & $\mathrm{P}$ \\
Alcalóides & $\mathrm{P}$ & $\mathrm{P}$ \\
Antraquinonas & $\mathrm{N}$ & $\mathrm{N}$ \\
Azulenos & $\mathrm{N}$ & $\mathrm{N}$ \\
Caratenóides & $\mathrm{N}$ & $\mathrm{N}$ \\
Catequinas & $\mathrm{P}$ & $\mathrm{P}$ \\
Depsídios e Depsidonas & $\mathrm{N}$ & $\mathrm{N}$ \\
Derivados Benzoquinonas & $\mathrm{N}$ & $\mathrm{N}$ \\
Derivados da Cumarina & $\mathrm{N}$ & $\mathrm{P}$ \\
Esteróides e Triterpenóides & $\mathrm{P}$ & $\mathrm{N}$ \\
Flavonóides & $\mathrm{P}$ & $\mathrm{P}$ \\
Glicosídios Cardíacos & $\mathrm{N}$ & $\mathrm{N}$ \\
Lactonas & $\mathrm{N}$ & $\mathrm{N}$ \\
Polissacarídios & $\mathrm{N}$ & $\mathrm{N}$ \\
Proteínas e Aminoácidos & $\mathrm{P}$ & $\mathrm{P}$ \\
Purinas & $\mathrm{N}$ & $\mathrm{N}$ \\
Saponinas Espumídicas & $\mathrm{N}$ & $\mathrm{N}$ \\
Taninos & $\mathrm{P}$ & $\mathrm{P}$ \\
\hline
\end{tabular}

$\mathrm{N}=$ a classe de aleloquímicos não foi identificada na fração da planta. $\mathrm{P}=$ a classe de aleloquímico foi identificadas na fração da planta.

Planta Daninha, Viçosa-MG, v.18, n.3, p.435-441, 2000
Neste estudo, os extratos aquosos preparados a partir das cascas das plantas de acapu apresentaram atividades potencialmente alelopáticas mais intensas do que os extratos das folhas, efeito esse demonstrado através das inibições mais intensas efetivadas sobre a germinação (Figura 1A e B) e o alongamento da radícula (Figura 2A e B) das duas plantas invasoras. Aparentemente, duas hipóteses podem ser levantadas para justificar esse resultado. Em primeiro plano, pode-se levantar a possibilidade de as substâncias alelopáticas, solúveis em água, comuns às cascas e folhas do acapu -alcalóides e flavonóides - estarem em maior concentração nas cascas. No entanto, partindose das classes de substâncias químicas identificadas nas duas frações da planta doadora (Tabela 2), é provável que as diferenças observadas estejam, ainda, associadas às diferenças na composição das classes químicas de substâncias alelopáticas. Poder-se-ia argumentar que as cumarinas, presentes apenas nas cascas, teriam maiores potencialidades para promover os resultados observados do que os esteróides e triterpenóides presentes apenas nas folhas do acapu. Por um lado, as cumarinas têm sido largamente relacionadas à alelopatia. Essas substâncias são apontadas como inibidoras potentes tanto do crescimento de plantas como da germinação de sementes (Rice \& Pancholy, 1973; Evenari, 1949). Em contrapartida, poucos esteróides e mesmo terpenóides têm sido relacionados à alelopatia, além do fato de que os terpenóides são apontados como de baixa solubilidade em água (Fischer, 1986), o que pode justificar os baixos efeitos do extrato aquoso das folhas do acapu.

\section{LITERATURA CITADA}

ASSUNÇÃO, R.M.V., MORITA, T. Manual de soluções e reagentes e solventes. São Paulo: Edgard Blücher, 1968. 627p.

BANSAL, G.L., BHAN, V.M. Status of research on allelopathy and future scope of work in India. Ind. J . Agric. Sci., v.63, n. 12, p.769-776, 1993.

CHOU, C.H. The role of allelopathy in subtropical agroecosystem in Taiwan. In: PUTNAM, A.R., TANG, C.S, (Eds.) The science of allelopathy. New York: John Willey \& Sons. 1986. p.203218. 
COPE, W.A. Inhibition of germination and seedling growth of eight forage species by leachates from seeds. Crop Sci., v.22, p.1109-1111, 1982.

CORCERA, L.J., ARGANDOÑA, V.M., ZUÑIGA, G.E. Allelochemicals in wheat and barley: role in plant insect interaction. In: RIZVI, S.J.H., RIZVI, V. (Eds.) Allelopathy. New York: Chapman \& Hall, 1992. p.119-127.

DURAN, J.M., TORTOSA, M.E. The effect of mechanical and chemical scarification on germination of charlock (Sinapis arvensis L.) seeds. Seed Sci. Technol., v.13, n.1, p.155-163, 1985.

EVENARI, M. Germination inhibitors. Bot. Rev., v.15, p.153-194, 1949.

FISCHER, N.H. The function of mono and sesquiterpens as plant germination and growth regulators. In: PUTNAM, A.R., TANG, C.S. (Eds.) The science of allelopathy. New York: John Willey \& Sons, 1986. p.203-218.

FRIEDMAN, J., WALLER, G.R. Seeds as allelopathic agents. J . Chem. Ecol., v.9, p.1107-1117, 1983.

HEISEY, R.M. Allelopathic and herbicidal effects of extracts from tree of heaven (Ailanthus altissima). Am. J . Bot., v.77, n.5, p.662-670, 1990.

JUNTILA, O. Seed and embryo germination in $S$. vulgaris and $S$. reflexa as effected by temperature during seed development. Physiol. Plant., v.29, p.264-268, 1976.

MACIAS, F.A. Allelopathy in the search of natural herbicide models. In: DAKISHINI, K.M.M., EINHELLIG, F.A. Allelopathy: organisms, processes and applications. Washington: American Chemical Society, 1995. p.310-329 (ACS. Symposium Series, 582).

PUTNAM, A.R. Weed allelopathy. In: DUKE, S.O. (Ed.) Weed physiology. Florida: CRS Press, 1985. p.131-155.

PUTNAM, A.R., DeFRANK, J. Use of allelopathic cover to inhibition weeds. In: CONGRESS PLANT PROT, 1981. Minneapolis. Proceedings... Minneapolis: 1982. p.580-582.

PUTNAM, A.R., TANG, C.S. Allelopathy: state of the science. In: PUTNAM, A.R.; TANG, C.S. (Eds.) The science of allelopathy. New York: John Wiley \& Sons, 1986. p.1-19.
RAO, A.S. Roots flavonoids. Bot. Rev., v.56, n.1, p. 1-55, 1990.

RICE, E.L. Allelopathy. New York: Academic Press, 1984. 422p.

RICE, E.L., PANCHOLY, S.K. Inhibition of nitrification by climax ecosystems. II. Aditional evidence and possible role of tannins. Am. J . Bot., v.60, p.691-702, 1973.

SAS - Statistical Analysis System. User's guide. Version 6. 4. ed. North Caroline: SAS Institute, 1989. 846p.

SMITH, A.E. The potential allelopathy characteristics of bitter sneezeweed (Helenium amarum). Weed Sci., v.37, p.665-669, 1989.

SMITH, A.E., MARTIN, D.L. Allelopathic characteristics of three cool-season grass in the forage ecosystems. Agron. J ., v.8, n.2, p.243246, 1994.

SOUZA FILHO, A.P.S. Potencialidades alelopáticas envolvendo gramíneas e leguminosas forrageiras e plantas invasoras de pastagens. Jaboticabal: UNESP, 1995. 137p. Tese (Doutorado em Zootecnia) - Universidade Estadual de São Paulo, 1995.

SOUZA FILHO, A.S., RODRIGUES, L.R.A., RODRIGUES, T.J.D. Efeitos do potencial alelopático de três leguminosas forrageiras sobre três invasoras de pastagens. Pesquisa Agropecuária Brasilei ra, v.32, n.1, p.165-170, 1997.

STOWE, L.G. Allelopathy and its influence on distribution of plants in Illinois old-field. J . Ecol., v.67, p.1065-1085, 1979.

UGAZ, O.L. Investigación fitoquímica: métodos en el estudio de productos naturales. Lima: Pontificia Universidad Catolica Del Peru, 1988. 213p.

WHITTAKER, R.H., FEENY, P.P. Allelochemies: chemical interaction between species. Science, v.171, p.757-770, 1971 .

YOUNG, C.C., BARTOLOMEW, D.P. Allelopathy in grass-legumes association. I-Effects of Hemarthria altissima (Poir) Stapf. and Hubb. Root residues on the growth of Desmodium intortum (Mill) Urb. and Hemarthria altissima in a tropical soil. Crop Science, v.21, p.770-774, 1981.

Planta Daninha, Viçosa-MG, v.18, n.3, p.435-441, 2000 